\title{
Attitude and practice toward physical restraint among psychiatric nurses in Guangdong, China: a cross-sectional survey ${ }^{\dagger}$
}

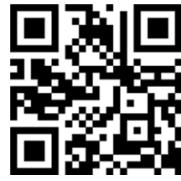

Original article

Jun-Rong Ye ${ }^{a, b}$, Jun-Fang Zeng ${ }^{c}$, Ai-Xiang Xiao ${ }^{a, d}, *$, Zhi-Chun Xia ${ }^{e}$, Lian-Di Daid ${ }^{d}$ Chen Wang ${ }^{f}$

${ }^{a}$ Department of Nursing Administration, Affiliated Brain Hospital of Guangzhou Medical University (Guangzhou Huiai Hospital), Guangzhou,

Guangdong 510370, China

${ }^{b}$ Department of Social Psychiatry, Affiliated Brain Hospital of Guangzhou Medical University (Guangzhou Huiai Hospital), Guangzhou, Guangdong

510370, China

'Department of Affect Disorder, Affiliated Brain Hospital of Guangzhou Medical University (Guangzhou Huiai Hospital), Guangzhou, Guangdong

510370, China

${ }^{\circledR}$ Department of Traditional Chinese Medicine, Affiliated Brain Hospital of Guangzhou Medical University (Guangzhou Huiai Hospital), Guangzhou, Guangdong 510370, China

${ }^{e}$ Department of Adult Psychiatry, Affiliated Brain Hospital of Guangzhou Medical University (Guangzhou Huiai Hospital), Guangzhou, Guangdong

510370, China

${ }^{t}$ Department of Early Intervention, Affiliated Brain Hospital of Guangzhou Medical University (Guangzhou Huiai Hospital), Guangzhou, Guangdong

510370, China

Received: 29 April 2020; Accepted: 22 June 2020; Published: 20 March 2021

Abstract: Objective: To explore the correlation between nurses' attitude and practice toward physical restraint (PR) in psychiatric settings and identify the factors that influence the use of PR.

Methods: A cross-sectional survey was conducted. A self-designed questionnaire containing a PR scale was used to assess the attitude and practice of registered psychiatric nurses in Guangdong, China, from November 1, 2018 to December 31, 2018. Descriptive statistics, the Mann-Whitney $U$ test, the Kruskal-Wallis test, and ordinal regression analysis were used to analyze the data.

Results: The response rate was $74.6 \%$. The nurses' responses showed neutral attitude and a moderate level of practice regarding the use of PR. Factors such as age, gender, marital status, professional position, nightshift, and the frequency of training programs on PR showed a significant association with nurses' attitude and practice concerning PR $(P<0.05)$. In addition to these factors, this study found that the practice of PR was associated with nurses' attitude toward it $(P<0.05)$. Our results showed that nurses with a largely negative attitude toward $P R$ were more likely to use it $(\mathrm{OR}=1.91, P<0.001)$.

Conclusions: Clinically, psychiatric nurses with negative attitude are more likely to practice PR. Training and education programs are highly recommended for nursing managers to change the nursing staff's attitude, since their attitude may have an impact on the PR what they practice.

Keywords: attitude $\bullet$ physical restraint $\bullet$ practice $\bullet$ psychiatric hospitals

(c) Shanxi Medical Periodical Press.

† This project was supported by Guangdong Science of Medical Technique Program (No. A2018440)

How to cite this article: Ye JR, Zeng JG, Xiao AX, Xia ZC, Dai LD, Wang C. Attitude and practice toward physical restraint among psychiatric nurses in Guangdong, China: a cross-sectional survey. Front Nurs. 2021;1:59-68.

* Corresponding author.

E-mail: 543061910@qq.com (A.-X. Xiao).

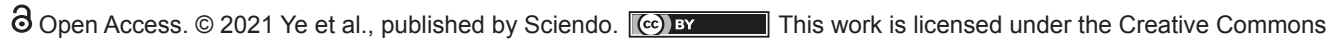
Attribution 4.0 License. 


\section{Introduction}

In psychiatric settings, unstoppable disruption and aggression result in critical impacts on patients and nursing staff. Under such circumstances, physical restraint (PR) is regarded as one of the potential approaches which guarantee the safety of patients and nurses. ${ }^{1} \mathrm{PR}$ refers to any manual method, material, or equipment that hinders the ability of a person to locomote or prevents an individual from moving freely. ${ }^{2}$ In China, PR is used as an alternative to cope with violent behaviors, manage patients with severe mental disorders, avoid injury, and reduce agitation. The common means of PR are devices designed to prevent a patient's body movements such as wrist or ankle ties, safety chest vests, and bandages. ${ }^{1}$

However, the application of PR is deemed as an arguable practice since it causes ethical and legal issues that violate patients' autonomy and dignity. ${ }^{3,4}$ Meanwhile, intellectual evidence supports the therapeutic effectiveness of restrictive measures in alleviating service users' aggression and violence. ${ }^{5,6}$ In contrast, empirical evidence has revealed that PR can lead to deleterious physical and psychological effects on both patients and nurses. From patients' point of view, PR is argued to cause physical issues such as skin damage, deep vein thrombosis, nervous system damage, or even death. ${ }^{7,8}$ Psychological issues involve demoralization, fear, anger, and losing dignity or respect. ${ }^{9,10}$ As for nurses, situations requiring application of PR represent an ethical dilemma and lead to considerably negative emotions such as frustration, fear, guilt, and anxiety. ${ }^{1}$

Despite the negative consequences arising out of PR use, nursing staffs are closely involved in the decision-making and implementation of PR. ${ }^{3,11}$ The absence of physicians' orders to activate or remove PR indicates that nurses are commonly key decision-makers on PR use. In addition, nursing staffs play a crucial role in determining the use of alternatives to $P R$ and ascertaining the duration and type of PR to be applied, which are usually based on their observations, assessment, and clinical experience. ${ }^{1}$ Given their obligation and responsibility of maintaining patient safety, most nurses believe that using PR is a feasible and necessary strategy in nursing care..$^{3,11}$ The nurses explained that the frequent use of PR was due to various factors, such as ensuring patients' safety, controlling aggressive patients, preventing interference with treatment, and avoiding disturbance to others. ${ }^{11,12}$

Researchers stressed that nurses' attitude and beliefs toward the use of PR are likely to be the most important determinants of its use, even though the organizational factors or clinical culture could affect the prevalence of the use of PR. ${ }^{10,13,14}$ In addition, the theory of reasoned action (TRA) developed by Fishbein and Ajzen ${ }^{15}$ interprets the relationship between behavior and attitude. For example, an individual's intention to behave in a certain manner is determined by his or her attitude. ${ }^{16}$ However, some studies showed that the practice of nurses regarding the use of PR was directly and indirectly associated with their level of knowledge and attitude concerning PR. ${ }^{13}$ In contrast, other studies concluded that nurses' attitudes did not predict their practice of PR. ${ }^{17}$ Therefore, further studies are needed to explain whether attitude could influence practice in relation to PR use. ${ }^{18}$

Researchers reported that psychiatric nursing staffs from different countries had different attitudes toward PR use; psychiatric nurses generally considered PR to be an appropriate method for coping with violence. . $^{3,10,18,19}$ Meanwhile, other experts suggest that nursing managers should implement relevant training programs to minimize PR use. Significantly, understanding the attitudes and practices toward PR helps to address training programs of regulating and reducing PR use. To our knowledge, limited studies have been conducted to explore psychiatric nurses' attitude and practice on PR in China. Therefore, this study aims to explore the correlation between attitude and practice toward PR in psychiatric settings. The specific objectives are to (1) identify nurses' attitude toward PR in psychiatric settings; (2) assess nurses' practice toward PR in psychiatric settings; and (3) evaluate the correlation between the attitude and practice of nurses toward PR in psychiatric settings.

\section{Methods}

\subsection{Study design}

This study was conducted via an online anonymous survey performed from November 1, 2018 to December 31, 2018.

\subsection{Participants}

The convenient sampling method was used to recruit psychiatric nurses in Guangdong, China. The inclusion criteria were (1) registered psychiatric nurses or licensed practical psychiatric nurses and (2) Chinese speakers. Nursing students were excluded.

\subsection{Study instruments}

Data were collected through a self-designed questionnaire, which includes participants' personal characteristics and Physical Restraint scale (PRS). The questionnaire was adjusted by researchers to make it 
easier for participants to understand. This self-designed questionnaire was tested by four nursing experts (faculty members from the nursing department and clinical nurses) who have $>20$ years of working experience in the psychiatric nursing setting.

\subsubsection{The first section}

This part included items pertaining to personal characteristics of psychiatric nurses including gender, age, marital status, educational level, working experience, professional position, and so on.

\subsubsection{Physical restraint scale}

PRS was initially developed by Suen et al. ${ }^{13}$ with a content validity index of $86 \%$. PRS was introduced into China and revised by Xia and Li. ${ }^{20}$ The scores of PRS were normalized into the summative bands using the Delphi method. The first part consists of 7 items measuring nurses' attitude toward using PR, rated on a 5-point Likert scale in which $4=$ "strongly agree" and 0 = "strongly disagree."

Participants were asked to respond whether they "strongly agree," "agree," "neutral," "disagree," or "strongly disagree." High score with cutoff point 20-28 reflects positive attitude, and low score with cutoff point 0-9 reflects negative attitude; on the other hand, scores of 10-19 reflect a neutral level (potential range: 0-28). A high score of PRS suggests that participants were more likely to use PR.

The second part contains 6 items measuring nurses' practice toward the use of $P R$, and the items were rated on a 5-point Likert scale in which $4=$ "strongly agree" and $0=$ "strongly disagree." Items 1, 3, 4, 5, and 6 were reverse-scored. Thus, a high score with cutoff point 17-24 reflects inadequate practice, and a low score with cutoff point $0-12$ reflects adequate practice; whereas 13-16 reflect a moderate level (potential range: 0-24). A low score suggests that participants used PR adequately in clinical practice.

In the current study, the Cronbach's alpha coefficients of the first and second parts were 0.66 and 0.78 , respectively. The validity of PRS (13 items) has been examined, and the Cronbach's alpha coefficient was 0.77 , indicating acceptable reliability and validity.

\subsection{Data collection}

After seeking approval from the nursing director of each psychiatric hospital that is registered in Guangdong Nursing Association (a non-governmental organization), the link of online-questionnaire was sent to the mailbox of the nursing administration department. The survey purpose, significance, and instructions were provided to ensure a high participation rate and obtain valid data. The nursing director of each psychiatric hospital helped the researchers to spread the questionnaires using WeChat app (a popular social application in China). All potential participants accessed the questionnaires and answered individually using WeChat via smartphones. Informed consent was presented on the first page of the online survey and was obtained before participants completed the online survey. To avoid repetition, a WeChat account was allowed to submit the questionnaire only once.

Data were collected online through the Chinese survey website named Wenjuanxing (www.sojump. com) from November 1, 2018 to December 31, 2018. A total of 1009 questionnaires were collected. The collected data were double-checked by two researchers (Cai and Xiao). Ultimately, 356 questionnaires were excluded because: (a) approximately 100 respondents indicated they worked outside Guangdong; (b) 128 questionnaires were with contradictions (for instance, the number of working years being in excess of age, age failing to match the professional position); and (c) 128 questionnaires were filled with identifiable errors. The number of the included qualified questionnaires were 753 , accounting for $74.6 \%$ of all returned questionnaires.

\subsection{Data analysis}

SPSS 21.0 Software Package was employed to analyze the data. Attitude and practice on PR use showed abnormal distributions (as examined by the Kolmogorov-Smirnov test). Descriptive statistics (frequency and percentage) were used to describe the participants' personal characteristics and profession information. The Mann-Whitney $U$ test and the Kruskal-Wallis test were used to determine whether the personal and professional characteristics had any effect on the scores of attitude and practices, respectively. In addition, ordinal regression analysis was administered to identify the correlation between attitude and practice related to PR. Confidence interval (CI) was set as $95 \%$. The significance level was set to 0.05 (two-tailed).

\subsection{Pilot study and sample size calculation}

A pilot study is usually employed to test the design of the large full-scale study, which then can be adjusted. ${ }^{21}$ In this study, the aim of the pilot study was to measure the simplicity of questionnaire and estimate the time needed 
for taking it. According to Thabane et al., ${ }^{21}$ the required sample for a pilot study would be at least 75 participants. Therefore, a pilot study was performed with 75 nurses to test the feasibility of the scales and instrument development. Simple modifications of the tools were done and all of these 75 questionnaires were excluded from the data analysis. Sample size was calculated by an online tool available at https://www.calculator.net. The minimum sample size was 385 , and we used a larger sample size.

\section{Results}

\subsection{Psychiatric nurses' personal data and professional characteristics}

The analysis of 753 psychiatric nurses' personal and professional characteristics demonstrated that almost half of them were aged between 25 and 35 years (47.9\%) (Table 1). A total of $77.0 \%$ of the nurses were female and more than half of them were married (63.6\%). Approximately half of the nurses (51.9\%) had obtained a bachelor's degree. Most of the nurses had a period of working experience which amounted to $<5$ years $(38.4 \%)$, and $75.4 \%$ of them were working in closed psychiatric wards. Further, most of them $(69.6 \%)$ were junior nurses. Only $22.7 \%$ of them were frequently given the opportunity to participate in training programs.

\subsection{The attitude toward PR among psychiatric nurses}

Regarding the attitude of psychiatric nurses toward PR use, $17(2.3 \%)$ of them showed scores that are $<9,480$ $(63.7 \%)$ had scores ranging from 10 to 19 , and 256 $(34.0 \%)$ had scores ranging from 20 to 28 . The total scores ranged from 4 to 27 (median $=18.00, \mathrm{SD}=$ 3.31), implying a neutral attitude (Table 2). The scores of each item are shown in Table 2. In total, most nurses agreed with the statement that "in emergencies, nurses are allowed to apply physical restraint for patients without a psychiatrist's order." About $30.4 \%$ disagreed with the statement that "in all cases, the reasons for physical restraint should be explained to the patient/family members and require their informed consent." About $55.4 \%$ of them agreed that "there should be standard process when implementing physical restraint." Approximately $55.6 \%$ agreed with the statement that "physical restraint would cause physical and psychological harm to patients," and $53.1 \%$ agreed that PR could easily lead to nurses' injury and psychological stress. Only 13\% strongly agreed that they had received enough training in terms of PR.

\begin{tabular}{|c|c|}
\hline Characteristics & $n(\%)$ \\
\hline \multicolumn{2}{|l|}{ Age (years) } \\
\hline$<25$ & $212(28.2)$ \\
\hline$<35$ & $361(47.9)$ \\
\hline$<45$ & $151(20.1)$ \\
\hline$>45$ & $29(3.9)$ \\
\hline \multicolumn{2}{|l|}{ Gender } \\
\hline Male & $173(23)$ \\
\hline Female & $580(77)$ \\
\hline \multicolumn{2}{|l|}{ Marital status } \\
\hline Single & $274(36.4)$ \\
\hline Married & $479(63.6)$ \\
\hline \multicolumn{2}{|l|}{ Education status } \\
\hline Secondary education degree & $73(9.7)$ \\
\hline Associate degree & $289(38.4)$ \\
\hline Bachelor's degree or above & $391(51.9)$ \\
\hline \multicolumn{2}{|l|}{ Working experience (years) } \\
\hline$<5$ & $289(38.4)$ \\
\hline$<10$ & $211(28.0)$ \\
\hline$<15$ & $101(13.4)$ \\
\hline$>15$ & $152(20.2)$ \\
\hline \multicolumn{2}{|l|}{ Professional position } \\
\hline Junior nurse & $524(69.6)$ \\
\hline Charge nurse & $193(25.6)$ \\
\hline Senior nurse & $36(4.8)$ \\
\hline \multicolumn{2}{|l|}{ Taking nightshift } \\
\hline Yes & $586(77.8)$ \\
\hline No & $167(22.2)$ \\
\hline \multicolumn{2}{|l|}{ Ward management model } \\
\hline Closed ward & $568(75.4)$ \\
\hline Non-closed ward & $185(24.6)$ \\
\hline \multicolumn{2}{|l|}{ Training program (frequency) } \\
\hline Rare & $281(37.3)$ \\
\hline Medium & $301(40.0)$ \\
\hline Often & $171(22.7)$ \\
\hline
\end{tabular}

Table 1. Participants' personal characteristics $(n=753)$.

\subsection{The practice related to PR among psychiatric nurses}

Concerning nurses' practice in relation to PR, 312 $(41.4 \%)$ of them showed scores that are $<12,242$ $(32.1 \%)$ had scores ranging from 13 to 16 , and 199 (26.4\%) had scores ranging from 17 to 24 . The scores were in the range of $3-24$ (median $=14, S D=4.49$ ), reflecting a moderate level of practice (Table 2). Totally, $74 \%$ of nurses agreed with the statement that "physical restraints would be applied when the patient is at risk of violence/suicide/escape", and $73.8 \%$ reported that they would consider whether alternative methods are adequate before implementing PR for the patient. 


\subsection{Factors affecting nurses' attitude and practice regarding PR use}

Table 3 shows the factors that affect nurses' attitude and practice regarding PR use. The Mann-Whitney $U$ test demonstrated that marital status, gender, and participating in nightshifts influenced their practice on PR use $(P<0.05)$. The Kruskal-Wallis test indicated that age, education status, working experience, professional position, and the frequency of training program influenced nurses' practice of restraint $(P<0.05)$. The attitude score was influenced by gender $(P=0.001)$, age $(P=0.002)$, professional position $(P=0.009)$, and the frequency of training program $(P=0.000)$.

\subsection{Correlation between nurses' attitude and practice toward PR use}

Table 4 presents the association between attitude and practice of nurses related to PR. The practice score was set as a dependent variable; the attitude

\begin{tabular}{|c|c|c|c|c|c|c|}
\hline \multirow[t]{2}{*}{ Items } & Frequency (\%) & Disagree & Neutral & \multirow[t]{2}{*}{ Agree } & \multirow[t]{2}{*}{ Strongly agree } & \multirow[t]{2}{*}{$M \pm S D$} \\
\hline & \multirow{2}{*}{\multicolumn{6}{|c|}{ Strongly disagree }} \\
\hline Attitude & & & & & & \\
\hline $\begin{array}{l}\text { 1. I fully understand the } \\
\text { definition and range of } \\
\text { application of PR. }\end{array}$ & $20(2.7)$ & $14(1.9)$ & $73(9.7)$ & $289(38.4)$ & 357 (47.4) & $3.26 \pm 0.90$ \\
\hline $\begin{array}{l}\text { 2. In emergencies, nurses } \\
\text { are allowed to apply PR } \\
\text { on patients without a } \\
\text { psychiatrist's order. }\end{array}$ & $38(5.0)$ & $40(5.3)$ & $97(12.9)$ & $211(28)$ & 367 (48.7) & $3.10 \pm 1.13$ \\
\hline $\begin{array}{l}\text { 3. In all cases, the reasons for } \\
\text { PR should be explained to } \\
\text { the patient/family members } \\
\text { and their informed consent } \\
\text { is required. }\end{array}$ & $35(4.6)$ & $70(9.3)$ & 132 (17.5) & 202 (26.8) & $314(41.7)$ & $2.92 \pm 1.17$ \\
\hline $\begin{array}{l}\text { 4. PR would cause physical } \\
\text { and psychological harm } \\
\text { to patients. }\end{array}$ & $33(4.4)$ & $68(9.0)$ & 235 (31.2) & 269 (35.7) & $148(19.7)$ & $2.57 \pm 1.04$ \\
\hline $\begin{array}{l}\text { 5. PR can easily lead to nurses' } \\
\text { injury and psychological } \\
\text { stress. }\end{array}$ & $43(5.7)$ & $113(15)$ & 197 (26.2) & $254(33.7)$ & $146(19.4)$ & $2.46 \pm 1.13$ \\
\hline $\begin{array}{l}\text { 6. There should be a standard } \\
\text { process when implementing } \\
\text { PR. }\end{array}$ & $6(0.8)$ & $13(1.7)$ & $56(7.4)$ & $261(34.7)$ & $417(55.4)$ & $3.42 \pm 0.77$ \\
\hline $\begin{array}{l}\text { 7. In terms of PR, I think I have } \\
\text { received enough training. }\end{array}$ & $47(6.2)$ & $138(18.3)$ & $240(31.9)$ & $230(30.5)$ & $98(13)$ & $2.26 \pm 1.09$ \\
\hline \multicolumn{7}{|l|}{ Practice } \\
\hline $\begin{array}{l}\text { 1. PR would be applied when } \\
\text { the patient is at the risk of } \\
\text { violence/suicide/escape. }\end{array}$ & $40(5.3)$ & $51(6.8)$ & 105 (13.9) & $191(25.4)$ & 366 (48.6) & $3.05 \pm 1.17$ \\
\hline $\begin{array}{l}\text { 2. Before implementing PR on } \\
\text { the patient, I would consider } \\
\text { whether alternative methods } \\
\text { are adequate. }\end{array}$ & $20(2.7)$ & $47(6.2)$ & $130(17.3)$ & 361 (47.9) & 195 (25.9) & $2.88 \pm 0.95$ \\
\hline $\begin{array}{l}\text { 3. PR can be applied for the } \\
\text { convenience of nursing } \\
\text { work. }\end{array}$ & $235(31.2)$ & $187(24.8)$ & $172(22.8)$ & $84(11.2)$ & $75(10)$ & $1.44 \pm 1.30$ \\
\hline $\begin{array}{l}\text { 4. I was influenced by my fellow } \\
\text { nurses when I implemented } \\
\text { PR on patients. }\end{array}$ & $171(22.7)$ & 198 (26.3) & 204 (27.1) & 125 (16.6) & 55 (7.3) & $1.59 \pm 1.21$ \\
\hline $\begin{array}{l}\text { 5. I was influenced by my } \\
\text { nursing superior when I } \\
\text { implemented PR on patients. }\end{array}$ & $153(20.3)$ & $169(22.4)$ & $192(25.5)$ & $172(22.8)$ & $67(8.9)$ & $1.78 \pm 1.25$ \\
\hline $\begin{array}{l}\text { 6. For patients who are difficult } \\
\text { to handle, junior nurses can } \\
\text { be recommended to use } \\
\text { PR appropriately for the } \\
\text { convenience of work. }\end{array}$ & 218 (29) & $180(23.9)$ & $194(25.8)$ & $96(12.7)$ & $65(8.6)$ & $1.48 \pm 1.27$ \\
\hline
\end{tabular}

Note: PR: physical restraint.

Table 2. Psychiatric nurses' attitude and practice toward $P R(n=753, M \pm S D)$. 


\begin{tabular}{|c|c|c|c|c|c|c|}
\hline Characteristics & Attitude & $t / F$ & $P$ value & Practice & $\mathrm{t} / \mathrm{F}$ & $P$ value \\
\hline Age (years) & & 14.995 & 0.002 & & 57.849 & 0.000 \\
\hline$<25$ & $17.94 \pm 3.26$ & & & $11.99 \pm 4.23$ & & \\
\hline $25-35$ & $18.02 \pm 3.37$ & & & $13.57 \pm 4.43$ & & \\
\hline $35-45$ & $19.04 \pm 3.05$ & & & $14.97 \pm 4.20$ & & \\
\hline$>45$ & $16.90 \pm 3.47$ & & & $17.00 \pm 4.18$ & & \\
\hline Gender & & -3.436 & 0.001 & & -3.622 & 0.000 \\
\hline Male & $18.79 \pm 3.69$ & & & $12.42 \pm 4.90$ & & \\
\hline Female & $17.97 \pm 3.17$ & & & $13.87 \pm 4.30$ & & \\
\hline Marital status & & -0.941 & 0.347 & & -4.740 & 0.000 \\
\hline Single & $18.06 \pm 3.26$ & & & $12.47 \pm 4.33$ & & \\
\hline Married & $18.21 \pm 3.35$ & & & $14.15 \pm 4.46$ & & \\
\hline Education status & & 2.425 & 0.489 & & 10.272 & 0.016 \\
\hline $\begin{array}{l}\text { Secondary } \\
\text { education } \\
\text { degree }\end{array}$ & $17.92 \pm 3.48$ & & & $12.44 \pm 4.56$ & & \\
\hline $\begin{array}{l}\text { Associate } \\
\text { degree }\end{array}$ & $17.94 \pm 3.23$ & & & $13.38 \pm 4.36$ & & \\
\hline Bachelor degree & $18.37 \pm 3.29$ & & & $13.95 \pm 4.49$ & & \\
\hline Master degree & $18.18 \pm 4.81$ & & & $11.00 \pm 5.40$ & & \\
\hline $\begin{array}{l}\text { Working experience } \\
\text { (years) }\end{array}$ & & 2.739 & 0.434 & & 37.429 & 0.000 \\
\hline$<5$ & $17.98 \pm 3.21$ & & & $12.67 \pm 4.35$ & & \\
\hline $5.00-10$ & $18.17 \pm 3.38$ & & & $13.35 \pm 4.45$ & & \\
\hline $10.01-15$ & $18.16 \pm 3.24$ & & & $13.61 \pm 3.97$ & & \\
\hline$>15$ & $18.47 \pm 3.46$ & & & $15.41 \pm 4.59$ & & \\
\hline $\begin{array}{l}\text { Professional } \\
\text { position }\end{array}$ & & 9.423 & 0.009 & & 28.092 & 0.000 \\
\hline Junior nurse & $17.92 \pm 3.30$ & & & $12.96 \pm 4.35$ & & \\
\hline Charge nurse & $18.69 \pm 3.19$ & & & $14.93 \pm 4.60$ & & \\
\hline Senior nurse & $18.81 \pm 3.79$ & & & $14.50 \pm 5.38$ & & \\
\hline Taking nightshift & & -2.360 & 0.018 & & -4.357 & 0.000 \\
\hline Yes & $17.99 \pm 3.31$ & & & $13.16 \pm 4.43$ & & \\
\hline No & $18.75 \pm 3.28$ & & & $14.86 \pm 4.47$ & & \\
\hline $\begin{array}{l}\text { Ward management } \\
\text { model }\end{array}$ & & -0.007 & 0.994 & & -0.988 & 0.323 \\
\hline Closed ward & $18.16 \pm 3.30$ & & & $13.65 \pm 4.40$ & & \\
\hline $\begin{array}{l}\text { Non-closed } \\
\text { ward }\end{array}$ & $18.28 \pm 3.35$ & & & $14.00 \pm 4.75$ & & \\
\hline $\begin{array}{l}\text { Training program } \\
\text { (frequency) }\end{array}$ & & 35.002 & 0.000 & & 11.227 & 0.004 \\
\hline Rare & $17.28 \pm 3.30$ & & & $13.12 \pm 4.24$ & & \\
\hline Medium & $18.46 \pm 3.11$ & & & $14.25 \pm 4.09$ & & \\
\hline Often & $19.06 \pm 3.31$ & & & $13.54 \pm 5.33$ & & \\
\hline
\end{tabular}

Abbreviation: PR, physical restraint.

Table 3. Attitude and practice toward PR among different nurses.

score was set as an independent variable; gender, age, working experience, and professional position were set as covariates of practice. Ordinal regression showed that nurses with a more negative attitude toward PR were more likely to use it $(\mathrm{OR}=1.91$, $P<0.001)$.

\section{Discussion}

\subsection{Nurses' attitude regarding PR use}

In this study, respondents demonstrated neutral attitude toward PR. However, some of them still held negative 


\begin{tabular}{|c|c|c|c|c|}
\hline Items & Estimate & OR & $95 \% \mathrm{Cl}$ & $P$ value \\
\hline Gender & 0.479 & 1.61 & 0.130 to 0.828 & 0.007 \\
\hline Age & 0.533 & 1.70 & 0.234 to 0.832 & $<0.001$ \\
\hline Marital status & -0.071 & 0.93 & -0.716 to 0.287 & 0.697 \\
\hline Education status & 0.196 & 1.22 & -0.020 to 0412 & 0.076 \\
\hline Profession title & -0.217 & 0.80 & -0.559 to 0.125 & 0.213 \\
\hline Work experience & 0.137 & 1.15 & -0.053 to 0.327 & 0.157 \\
\hline Taking nightshift & 0.113 & 1.12 & -0.321 to -0.546 & 0.610 \\
\hline Training program & 0.250 & 1.28 & 0.057 to 0.442 & 0.011 \\
\hline Attitude & 1.811 & 6.12 & 0.903 to 2.719 & $<0.001$ \\
\hline
\end{tabular}

Note: This parameter was set to zero because it is redundant.

Table 4. Ordinal regression analysis for the correlation between attitude and practice

attitude toward PR. For example, about 33\% disagreed with the statement that "in all cases, the reasons for physical restraint should be explained to the patient/ family members and require their informed consent." This result of the current study was similar to the findings of the Mahmoud study, ${ }^{1}$ which revealed that about $34 \%$ of participants did not agree that family members had the right to refuse the use of PR. This may be due to the rare involvement of ethical issues regarding PR use in training or nursing program education. ${ }^{22}$ This study indicates the need to increase the awareness of nurses towards patients' rights and the ethical issues related to the use of PR to protect patients' autonomy and rights.

In addition, in our study, about $76.7 \%$ agreed with the statement that "in emergencies, nurses are allowed to apply physical restraint for patients without a psychiatrist's order." We found in agreement with other studies that most nurses reported that using PR does not need a doctor's order. ${ }^{23,24}$ Our study revealed that PR was commonly employed and removed according to the nurses' subjective clinical judgment. Indeed, the decision to apply $\mathrm{PR}$ is not an easy one, and the nursing staff revealed that it is an ethical dilemma. ${ }^{4}$ However, it must be noted that if $\mathrm{PR}$ is decided to be implemented for patients who lack capacity, their fundamental rights and freedom must be respected and protected to the maximum extent and their best interests should be maintained. ${ }^{1}$

Furthermore, only about $40 \%$ agreed that they had received enough training in terms of $P R$, and the level of degree of this item is relatively low. Our study indicates that the training needs of nurses were strong regarding PR. Therefore, it is important to note that nursing managers and leaders of nursing institutions should pay more attention in adopting effective training strategies to effect the nursing staff's attitude and enhance their understanding of PR. The purpose of this exercise is to inspire nurses to proactively seek alternatives to PR and attempt to minimize the use of PR. ${ }^{22}$

\subsection{Psychiatric nurses' practice related to the use of PR}

Regarding the scores for nursing practice, the results of this study indicate that psychiatric nurses have a moderate level of practice related to PR use. The results of our study revealed that $74 \%$ of nurses agreed that PR should be applied when the patient is at risk of violence, suicide, or escape. This finding reflected their agreement on using PR for psychiatric patients. Such a finding could be explained in terms of the fact that that nurses perceived agitated psychiatric patients as being dangerous, and they agreed to use PR to reduce the patients' dangerous behaviors to ensure safety. In addition, it may be explained that nurses tend to be more likely to use $\mathrm{PR}$ for the convenience of their own work, especially when the nursing assignment is heavy and supervision capacity is limited. ${ }^{25}$ Further study supporting this evidence was found by Mahmoud ${ }^{1}$ and $\mathrm{Al}$ and Hasan. ${ }^{10}$

However, concerning finding alternative approaches, $73.8 \%$ of the respondents reported that they would consider whether alternative methods are adequate before implementing the PR for patients. In contrast to some other studies, ${ }^{13,24}$ the majority of our participants had shown awareness concerning alternatives to PR. The results of our study are consistent with the Mahmoud ${ }^{1}$ findings, which showed that $94.7 \%$ of the participants would try alternative nursing measures before restraining patients. ${ }^{1}$ Through standardized training, nurses would be able to apply PR more rationally. Nevertheless, in the current study, there were still about $30 \%$ of participants who demonstrated that they failed to find alternatives to PR. Therefore, introducing and focusing on alternatives to PR would be a vital topic in restraint minimization training programs.

Finally, in our study, approximately $21.5 \%$ of the respondents agreed that PR could be applied for the convenience of nursing work, and junior nurses could be recommended to use PR appropriately for the 
convenience of work. The findings of this study revealed that part of the nursing staff misused PR. This, to some extent, may be due to the workforce shortage in psychiatric institutions in China. An inadequate number of psychiatric nurses care for a considerable number of psychiatric patients; this leads to their heavy workload, which is considered to be one of the critical reasons of the prevalent use of PR. ${ }^{4}$ However, through these findings we hope to offer evidence for nursing managers and policy-makers who are developing targeted intervention strategies of regulating the use of PR that would benefit clinical practice.

\subsection{Factors affecting nurses' attitude and practice regarding PR use}

This study found that nurses within the age group of 35-45 years had much higher attitude scores than the nurses from other age groups $\left(\chi^{2}=14.995, P=0.002\right)$. This finding indicated that psychiatric nurses were influenced by the experiences that they have learned during the period of their employment as a psychiatric nurse. Those nurses who were aged between 35 and 45 years were the most senior nurses, possibly because senior nurses were more experienced, and continuous training to some extends help to change the nurses' attitude toward PR. This finding is generally in line with Wang et al. ${ }^{22}$ and Mahmoud. ${ }^{1}$

The present study revealed that nurses aged $>45$ performed practice inadequately, whereas nurses aged below $<25$ years performed better, from which it was found that the level of nurses' practice concerning PR decreased with older nurses $\left(\chi^{2}=57.849\right.$, $P=0.001)$. These findings are inconsistent with the study by Mahmoud ${ }^{1}$ which concluded that experienced professionals' age-wise, older nurses tended to make better adjustments than younger nurses. This is mainly related to the decrease of frequency of training in $\mathrm{PR}$ among these older-age nurses. Furthermore, the male nurses have higher attitude and lower practice scores ( $Z=-3.436, P=0.001 ; Z=-3.622, P=0.001)$, and this reveals that male nurses showed better attitude and performed better skills in relation to PR.

It is interesting to note that nurses who received more than 6 times the length of training program related to PR showed better attitude and performed better than those who received $<4$ times the length of training program $\left(\chi^{2}=35.002, P=0.001 ; \chi^{2}=11.227, P=0.004\right)$. This finding, to some extent, reveals that implementing a training program related to PR would be an effective approach in enhancing nurses' attitude and improving their practice in relation to PR. There were no significant differences between nurses' other demographic and professional characteristics and attitude and practice scores in using PR. In brief, each psychiatric institution can find out the weak links in the institution according to the above affecting factors that influence the use of PR and improve the awareness of PR of psychiatric nurses through different training programs.

\subsection{The correlation between attitude and practice related to $P R$}

In harmony with the conclusions reached in the literature of Suen et al. ${ }^{13}$ and Werner, ${ }^{16}$ this study found that the practice related to PR was associated with nurses' attitude toward PR use. Specifically, through ordinal regression analysis, we found nurses with a more negative attitude toward PR were more likely to use it $(P<0.001)$. "Negative attitude" means the nursing staff in the study of Suen et al., ${ }^{13}$ the path analysis indicated that nursing staff' attitude had positive direct effects on PR use, which was similar to the result of the current study. Likewise, in their study, Werner ${ }^{16}$ found after using regression analyses that participants' attitudes were significantly associated with intention to use PR. In addition, our findings support the conclusions of other researchers that the nursing staff's attitude and beliefs are important determinants of PR use. ${ }^{10,13}$ In the study by Eskandari et al. ${ }^{24}$ multiple linear regression showed that only $6 \%$ of variations in nurses' practice was explained by participants' attitude and intention concerning PR. The reason for their result could be that, although nurses' attitude and intention were influencing factors of nurses' practice, other factors could have existed to affect nurses' practice regarding PR. However, in our study, to identify the correlation between nurses' attitude and practice, we employed the ordinal regression model to control the factors influencing practice regarding PR use, to a greater extent showing that nurses' attitude can affect the practice of $P R$.

Therefore, we proposed that nurses' attitude was the main determinant of intention to use PR in psychiatric settings. There are two major possible explanations regarding this finding. First, from the theoretical perspective, similar to the findings of the other study using the TRA with nurses, ${ }^{16}$ it may be proposed that nurses' personal beliefs and attitude about the use of PR are more potent in determining their intention when compared with other factors. The second explanation may be related to the environmental and cultural background of this study. Although there currently exist guidelines governing the application of PR in relation to mentally ill patients in China, there is still a lack of coercion supervision from the nursing administration department or the 
third party with regard to PR use in psychiatric settings. ${ }^{4}$ Thus, the intention to use PR may be mainly influenced by nurses' personal attitude rather than organizational factors or ward culture.

\section{Conclusions}

In this study, neutral attitude and a moderate level of practice regarding the use of PR were found among psychiatric nurses. Nurses with a negative attitude were found to be more likely to practice PR. Additionally, some psychiatric nurses still held misunderstandings on some crucial areas of PR use. All of these findings indicate that there exists a need for implementing more education and training programs for nursing staff, particularly to address the change of nurses' attitude toward PR, ethical considerations, and alternatives related to PR. Furthermore, targeted intervention strategies should be developed to reduce unnecessary PR use and to regulate the use of PR in cases wherein it is unavoidable.

\section{Strengths and limitations}

To our knowledge, this study was the first to examine the attitude toward PR among Chinese psychiatric nurses using large a sample size. Thus, the findings are expected to provide evidence and references for

\section{References}

1. Mahmoud AS. Psychiatric nurses' attitude and practice toward physical restraint. Arch Psychiatr Nurs. 2017;31:2-7.

2. Ye J, Wang C, Xiao A, et al. Physical restraint in mental health nursing: a concept analysis. Int $J$ Nurs Sci. 2019;6:343-348.

3. Vedana KGG, da Silva DM, Ventura CAA, et al. Physical and mechanical restraint in psychiatric units: perceptions and experiences of nursing staff. Arch Psychiatr Nurs. 2018;32:367-372.

4. Ye J, Xiao A, Yu L, Wei H, Wang C, Luo T. Physical restraints: an ethical dilemma in mental health services in China. Int J Nurs Sci. 2018;5:68-71.

5. Mohr WK. Restraints and the code of ethics: an uneasy fit. Arch Psychiatr Nurs. 2010;24:3-14.

6. Voskes Y, Kemper M, Landeweer EG, Widdershoven GA. Preventing seclusion in psychiatry: a care ethics perspective on the first five minutes at admission. Nurs Ethics. 2014;21: 766-773.

7. Di Lorenzo R, Miani F, Formicola V, Ferri P. Clinical and organizational factors related to the reduction of mechanical restraint application in an acute ward:
Chinese nursing managers to implement training programs and develop corresponding interventions to reduce $P R$ use in psychiatric hospitals.

The convenience sample was used in this study, which may influence the generalization of our findings. Further researches employ mixed methods to comprehensively gain additional in-depth and valuable results.

\section{Ethical approval}

This study was approved by the Hospital Research Ethics Committee and Guangdong Science of Medical Technique Program (No: A2018440). The main purpose of the study was elucidated to respondents at the beginning of the questionnaire and consent was obtained. The subjects were informed that the questionnaire was anonymous and that the potential revelation of information on personal social media was not involved. The participants noted that participation was voluntary and that they could exit filling the questionnaire at any time.

\section{Conflicts of interest}

All contributing authors declare that no conflicts of interest exist.

an 8-year retrospective analysis. Clin Pract Epidemiol Mental Health. 2014;10:94-102.

8. Rakhmatullina M, Taub A, Jacob T. Morbidity and mortality associated with the utilization of restraints a review of literature. Psychiatr Q. 2013;84:499-512.

9. Spinzy Y, Maree S, Segev A, Cohen-Rappaport $\mathrm{G}$. Listening to the patient perspective: psychiatric inpatients' attitudes towards physical restraint. Psychiatr Q. 2018;89:691-696.

10. Al A, Hasan H. Psychiatric nurses' knowledge, attitudes, and practice towards the use of physical restraints. Perspect Psychiatr Care. 2018;55:218-224.

11. Jiang H, Li C, Gu Y, He Y. Nurses' perceptions and practice of physical restraint in China. Nurs Ethics. 2014;22:652-660.

12. Gelkopf M, Roffe Z, Behrbalk P, Melamed Y, Werbloff N, Bleich A. Attitudes, opinions, behaviors, and emotions of the nursing staff toward patient restraint. Issues Mental Health Nurs. 2009;30:758-763.

13. Suen LK, Lai CKY, Wong TKS. Use of physical restraints in rehabilitation settings: staff knowledge, attitudes and predictors. JAdv Nurs. 2006;55:20-28. 
14. Zhu XM, Xiang YT, Zhou JS, et al. Frequency of physical restraint and its associations with demographic and clinical characteristics in a Chinese psychiatric institution. Perspect Psychiatr Care. 2014;50:251-256.

15. Fishbein M, Ajzen I. Belief, Attitude, Intention, and Behavior: An Introduction to Theory and Research. New York: Addison-Wesley Publishing Co.; 1975.

16. Werner P. Nursing staff members' intentions to use physical restraints with older people: testing the theory of reasoned action. $J$ Adv Nurs. 2001;35:784-791.

17. Myers H, Nikoletti S, Hill A. Nurses' use of restraints and their attitudes toward restraint use and the elderly in an acute care setting. Nurs Health Sci. 2001;3:29-34.

18. Göktaş A, Buldukoğlu K. Determination of psychiatric clinic nurses' knowledge, attitudes, and practices regarding the use of physical restraints. J Psychiatr Nurs. 2018;9:1-10.

19. Gandhi S, Poreddi V, Palaniappan M, Reddy SSN, Badamath S. Indian nurses' knowledge, attitude and practice towards use of physical restraints in psychiatric patients. Invest Educ Enferm. 2018;36:e10.

20. Xia CH, Li Z. Intensive care unit nurses' knowledge, attitude and behavior toward physical restraint. Chin J Nurs. 2008;43:568-570 (in Chinese).

21. Thabane L, Ma J, Chu R, et al. A tutorial on pilot studies: the what, why and how. BMC Med Res Methodol. 2010;10:1.

22. Wang L, Zhu XP, Zeng XT, Xiang P. Nurses' knowledge, attitudes and practices related to physical restraint: a cross-sectional study. Int Nurs Rev. 2018; 66:122-129.

23. Constantin J. Physical restraint in mechanically ventilated ICU patients: a survey of French practice. Intensive Care Med. 2013;39:31-37.

24. Eskandari F, Khatijah LA, Zainal N, Wong LP. Use of physical restraint: Nurses' knowledge, attitude, intention and practice and influencing factors. J Clin Nurs. 2017;26: 4479-4488.

25. Yang Y, Zhou WQ, Xia ZC, et al. Investigation and analysis of protective restraint awareness and influencing factors of psychiatric nurses. China Mod Med. 2019;26:174-177 (in Chinese). 